\title{
Optimal management of oropharyngeal and esophageal candidiasis in patients living with HIV infection
}

This article was published in the following Dove Press journal:

HIVIAIDS - Research and Palliative Care

27 April 2010

Number of times this article has been viewed

\section{Jose A Vazquez}

Division of Infectious Diseases, Henry Ford Hospital, Wayne State University School of Medicine, Detroit, MI, USA
Correspondence: Jose A Vazquez Henry Ford Hospital, Division of Infectious Diseases, 2799 West Grand Boulevard, CFP 202, Detroit, MI, 48202, USA

Tel + I 3/3 9162573

$\mathrm{Fax}+\mathrm{I} 3139163424$

Email jvazquel@ihfhs.org
Abstract: Mucocutaneous candidiasis is frequently one of the first signs of human immunodeficiency virus (HIV) infection. Over $90 \%$ of patients with AIDS will develop oropharyngeal candidiasis (OPC) at some time during their illness. Although numerous antifungal agents are available, azoles, both topical (clotrimazole) and systemic (fluconazole, itraconazole, voriconazole, posaconazole) have replaced older topical antifungals (gentian violet and nystatin) in the management of oropharyngeal candidiasis in these patients. The systemic azoles, are generally safe and effective agents in HIV-infected patients with oropharyngeal candidiasis. A constant concern in these patients is relapse, which is dependent on the degree of immunosuppression commonly seen after topical therapy, rather than with systemic azole therapy. Candida esophagitis (CE) is also an important concern since it occurs in more than $10 \%$ of patients with AIDS and can lead to a decrease in oral intake and associated weight loss. Fluconazole has become the most widely used antifungal in the management of mucosal candidiasis. However, itraconazole and posaconazole have similar clinical response rates as fluconazole and are also effective alternative agents. In patients with fluconazole-refractory mucosal candidiasis, treatment options now include itraconazole solution, voriconazole, posaconazole, and the newer echinocandins (caspofungin, micafungin, and anidulafungin).

Keywords: oropharyngeal candidiasis, esophageal candidiasis, HAART, antifungal agents, HIV, AIDS

\section{Introduction}

Fungi are found ubiquitously in nature in association with plants and mammals. Accordingly, humans are continually exposed to multiple genera of fungi via various routes, but particularly by the ingestion of food, allowing for the colonization of the gastrointestinal tract. Depending on the interaction between the host's mucosal defense mechanisms, fungal virulence factors, and antifungal utilization, colonization may be transient or persistent and local disease may ensue.

Of the numerous pathogenic fungi, Candida is the dominant genus responsible for fungal diseases in humans. ${ }^{1}$ Candida albicans is the species with the highest prevalence among human yeast isolates and is the main opportunistic yeast pathogen in most warm-blooded animals. ${ }^{1}$

Symptomatic mucosal candidiasis (MC) arises in subjects colonized with Candida who are predisposed by illness, debility, or a local reduction in host resistance to an overgrowth of their own indigenous flora. Candida species are frequently isolated from the oral cavity and are detected in $31 \%-60 \%$ of healthy individuals. ${ }^{1,2}$ Colonization rates generally increase with the severity of illness and duration of hospitalization. ${ }^{3}$ 
In a recent study, the frequency of oral yeast carriage in the competent host varied as a function of age. ${ }^{2}$ The colonization rates increase from $24 \%$ in persons aged 5-7 years, to $59 \%$ in persons above the age of 60 . In the hospitalized non-HIV infected individual, $C$. albicans accounted for $70 \%-80 \%$ of oral isolates and $C$. glabrata and $C$. tropicalis each represented approximately 5\%-8\%, while the other non-albicans Candida species were recovered only rarely. ${ }^{4,5}$

In the past decade, there has been a significant increase in the frequency of non-albicans Candida species isolated from HIV-infected individuals with MC. ${ }^{6,7}$ In the 1980's, non-albicans Candida species accounted for $3.4 \%$ of oral isolates from HIV-infected patients, while in the 1990 's, $16.8 \%$ of isolates recovered from HIV patients were non-albicans Candida species. ${ }^{6,7}$ The more commonly recovered non-albicans Candida species, include C. glabrata, C. parapsilosis, C. tropicalis, and $C$. dubliniensis. In 5\%-10\% of circumstances multiple Candida species may be recovered from a single specimen. The more common combinations include $C$. albicans with $C$. glabrata, C. krusei, C. dubliniensis, or C. tropicalis.

Several local and systemic host and exogenous factors increase the prevalence of gastrointestinal (GI) tract Candida carriage and population levels. ${ }^{8}$ The acuteness and extent of candidal infections increase with the number and severity of predisposing factors. The role of $\mathrm{CD}^{+} \mathrm{T}$ cells is to be the normal gastrointestinal mucosal defense mechanism against Candida species and this relation is highlighted by the frequent occurrence of oropharyngeal candidiasis (OPC) and esophageal candidiasis (EC) in patients with low $\mathrm{CD}^{+} \mathrm{T}$ cells and acquired immunodeficiency syndrome (AIDS).$^{8,9}$ In HIV infection, oral carriage of yeast and risk of mucosal invasion increase with a progressive reduction in $\mathrm{CD} 4^{+} \mathrm{T}$ cells. ${ }^{8,10}$ The anti-Candida protective mechanism of $\mathrm{CD}^{+} \mathrm{T}$ cells at a mucosal level is still incompletely understood. Recently, investigators have shown that cytokines, especially gamma interferon, can inhibit the transformation of Candida blastoconidia to the more invasive hyphal phase. ${ }^{8,11}$ In addition, several investigators have shown that a decrease in E-cadherin levels and a loss of $\mathrm{CD}^{+} \mathrm{T}$ cells in the mucosa are associated with episodes of acute OPC. ${ }^{12}$ The most commonly reported cause of higher GI yeast carriage rates and symptomatic oral candidiasis is the use of antibiotics. ${ }^{1,8}$ Elimination of bacterial competition is almost certainly the important mechanism by which antibiotics affect Candida numbers in vivo.

It is important to note that the introduction of highly active antiretroviral therapy (HAART), including protease inhibitors, has significantly reduced the prevalence of oropharyngeal and esophageal candidiasis in HIV-infected patients. In the first 12-24 months after the introduction of HAART, the prevalence of OPC decreased from 50\%-80\% down to $\sim 10 \%$. ${ }^{13}$ In addition, a decrease of $25 \%-50 \%$ in the occurrence of EC was also documented. Unfortunately, there have been no further studies describing the epidemiology, incidence, or significance of either OPC or EC since 2004.

Based upon epidemiological studies, it is apparent that humans are exposed repeatedly to Candida in food and other sources. The natural history of this commensal "normal" colonization over weeks, months, and years is poorly understood. Nevertheless, one may reasonably conclude that Candida colonization is almost universal.

\section{Oropharyngeal candidiasis}

Oral candidiasis has been known since the era of Hippocrates, although Hippocrates used the term "aphthae" to describe this infection. ${ }^{1}$ Several clinical forms of oral candidiasis exist; thrush is the most commonly and widely recognized and is also called acute pseudomembranous candidiasis (Figure 1). Oropharyngeal candidiasis remains the most frequent opportunistic fungal infection among HIV-positive patients and is frequently the initial manifestation of HIV infection. Currently, it is estimated that approximately $80 \%-90 \%$ of HIV-infected patients develop OPC at some time during the progression of their disease from HIV infection to AIDS. ${ }^{1,13,14,15}$

C. albicans is the species responsible for the majority of cases of OPC. ${ }^{1,15}$ The ability of C. albicans to adhere to buccal epithelial cells is critical in establishing oral colonization. After colonization, the organisms may persist for months or years in low numbers in the absence of inflammation. These low numbers are the result of effective host defense mechanisms in the oral cavity. Genotyping of Candida strains obtained from HIVinfected patients with either OPC or EC indicate a genotype distribution frequency similar to that seen in non-HIV-infected subjects, suggesting that HIV-associated MC is not caused by a unique or particularly virulent strain of Candida, but likely results from defects in host defense mechanisms. ${ }^{16}$

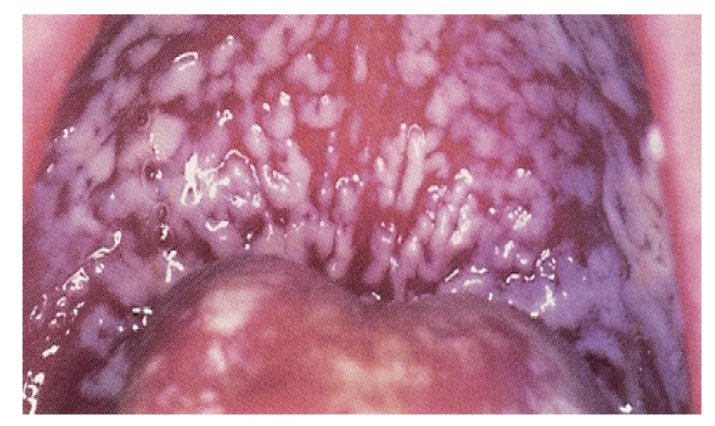

Figure I Pseudomembranous oropharyngeal candidiasis. 
Symptoms of OPC can be extremely variable and range from asymptomatic oral lesions, to a sore, painful mouth, a burning tongue, and associated dysphagia. Clinical signs include diffuse erythema and white patches that appear as discrete lesions on the surfaces of the buccal mucosa, throat, tongue, and gums. ${ }^{1,14}$ Severe OPC may ultimately impair quality of life and result in a reduction of fluid or food intake. The most serious complication of untreated OPC is extension of the infection into the esophagus resulting in decreased nutritional intake.

\section{Candida esophagitis}

Candida is the most common cause of infectious esophagitis and, after the oropharynx, the esophagus is the second most common site of gastrointestinal candidiasis. The prevalence of Candida esophagitis (CE) has increased mainly because of its association with HIV-infected individuals. Approximately $10 \%-15 \%$ of patients with AIDS will eventually suffer from this entity during their lifetime. ${ }^{1,15,17-19}$

The same organisms that are recovered from the esophageal surface are generally the same organisms identified in oral secretions. C. albicans remains the most common organism identified in CE. In contrast to oral candidiasis, little is known about host and yeast factors operative in the pathogenesis of esophageal candidiasis and experimental models have not been established. However, it is likely that the usual yeast virulence factors and defects in host defense mechanisms are responsible. Esophageal candidiasis in HIV-positive patients may be the first manifestation of AIDS. The high prevalence of esophagitis in connection to AIDS indicates the critical role of cell-mediated immunity in normally protecting the esophagus from Candida invasion. Candida esophagitis tends to occur later in the natural history of HIV infection and almost invariably at lower $\mathrm{CD}^{+} \mathrm{T}$ cell counts (range 10-105, mean 79, median 30 cells). ${ }^{1,17-19}$ It is not uncommon for patients with advanced AIDS, and near the end of life, suffering from severe esophageal candidiasis manifested by the inability to have any form of oral intake.

Candida esophagitis commonly causes dysphagia, odynophagia, and retrosternal pain. Although CE may arise as an extension of OPC, in approximately $10 \%$ of cases the esophagus maybe the only site involved affecting the distal two-thirds, rather than the proximal one-third, which is the area more commonly affected (Figure 2 ). An occasional feature of $\mathrm{CE}$ is the complete lack of clinical symptoms despite extensive objective esophageal involvement. ${ }^{1,17-19}$

A reliable diagnosis can only be made by direct visualization of the esophagus along with histological evidence of tissue invasion in biopsy material. ${ }^{22,21}$ However,

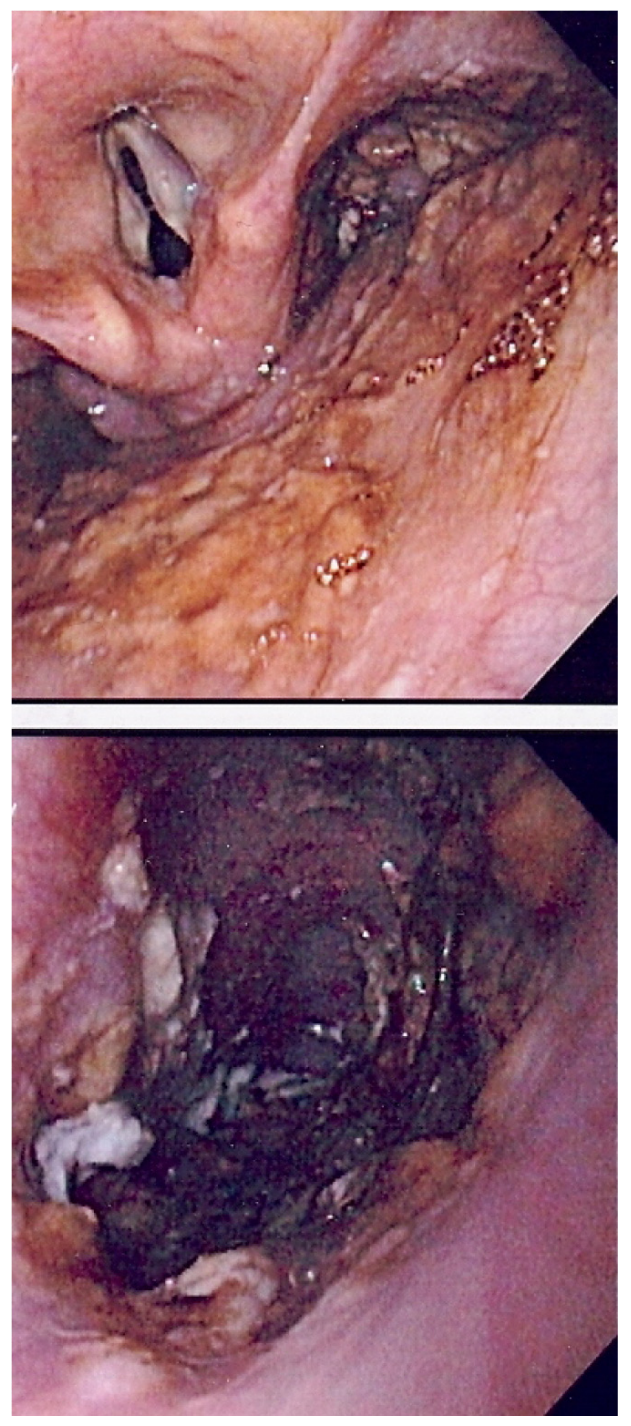

Figure 2 Esophageal candidiasis.

clinical criteria may be accepted as a basis for initiating antifungal therapy in high risk patients. The differential diagnosis of EC must include gastroesophageal reflux disease (GERD), idiopathic HIV-ulcers, and viral esophagitis due to either cytomegalovirus or herpes simplex virus. ${ }^{1,20,21}$

\section{Therapy}

Numerous antifungal agents are available for the treatment of OPC and EC in the HIV-positive patient (Tables 1 and 2). In addition, guidelines for the management of mucosal candidiasis in HIV-infected patients have been published by the Centers for Disease Control, National Institutes of Health, and the HIV Medicine Association of the Infectious Diseases Society of America. ${ }^{22}$ However, several factors should be considered when selecting antifungal agents for patients with HIV infection. In HIV-positive patients, antifungals are frequently less efficacious than in patients with other immunodeficiencies such as 
Table I Antifungals for oropharyngeal candidiasis*

\begin{tabular}{|c|c|c|c|c|}
\hline Antifungal agent & Form & Strength & Usage & Cost \\
\hline \multicolumn{5}{|l|}{ Topical } \\
\hline \multirow[t]{3}{*}{ Nystatin } & Pastille & 200000 units & I-2 pastilles, 4 times daily & + \\
\hline & Suspension & & $5 \mathrm{~mL}$ swish-and-Swallow, & + \\
\hline & & & 4 times daily & + \\
\hline \multirow[t]{2}{*}{ Clotrimazole } & Oral troche & $10 \mathrm{mg}$ troche & Dissolve I troche, 5 & + \\
\hline & & & times daily & \\
\hline \multirow[t]{4}{*}{ Amphotericin B } & Suspension & $\mathrm{I} \mathrm{mg} / \mathrm{mL}$ & I mL swish-and- & + \\
\hline & & & swallow, 4 times daily & \\
\hline & Lozenge & $100 \mathrm{mg}$ & Four times daily & + \\
\hline & Tablet & $10 \mathrm{mg}$ & Four times daily & + \\
\hline Miconazole & Lauriad & $10 \mathrm{mg}$ & Apply to gum once daily & TBD \\
\hline \multicolumn{5}{|l|}{$\left(\right.$ Lauriad $\left.^{\circledR}\right)$} \\
\hline \multicolumn{5}{|l|}{ Systemic } \\
\hline \multirow[t]{2}{*}{ Ketoconazole } & Tablet & $200 \mathrm{mg}$ & $\mathrm{I}-2$ tablets, once to & + \\
\hline & & & twice daily & \\
\hline \multirow[t]{2}{*}{ Fluconazole } & Tablet & $100 \mathrm{mg}$ & I tablet daily & ++ \\
\hline & Solution & $10 \mathrm{mg} / \mathrm{mL}$ & $10 \mathrm{~mL}$, once daily & ++ \\
\hline \multirow[t]{2}{*}{ Itraconazole } & Capsule & $100 \mathrm{mg}$ & 2 capsules, once daily & ++ \\
\hline & Solution & $10 \mathrm{mg} / \mathrm{mL}$ & I0-20 mL, once daily & ++ \\
\hline Posaconazole & Suspension & $100 \mathrm{mg} / 2.5 \mathrm{~mL}$ & 2 tsp daily & +++ \\
\hline
\end{tabular}

Notes: *Oral therapy preferred when tolerated. Cost index: $(+)$ inexpensive; $(++)$ modest expense; $(+++)$ expensive; TBD = to be determined.

cancer. Similarly, the time to clinical response also tends to be delayed in this population..$^{17,22,23}$ Moreover, the relapse rate is higher in patients with HIV than in any other patient population. ${ }^{1,17,22,23}$ For unknown reasons, a subgroup of HIV-positive patients experience recurrent episodes of OPC and thus receive numerous courses of antifungals during their lifetime. As their HIV infection progresses they tend to experience shorter disease-free intervals between episodes of mucosal candidiasis and thus have greater antifungal exposure, which may ultimately lead to the development of clinical and in vitro antifungal resistance and its associated morbidity and mortality.

It is important to note that, as with some opportunistic pathogens in this patient population, antifungal treatment merely reduces the signs and symptoms of infection and thus produces a transient clinical response by lowering the quantity of organisms in the affected area. It is extremely difficult to fully eradicate Candida from the mucosal surfaces of patients who are immunocompromised, especially those who are HIVpositive. ${ }^{8,18,23}$ The combination of frequent clinical relapses and increased antifungal utilization are frequently associated with antifungal resistance..$^{24}$ This is reflected, clinically, by the ineffectiveness of antifungals to which a patient has not previously been exposed. Thus, we are becoming increasingly aware that choosing the appropriate agent, even in the early stages of disease, is extremely important because of the future repercussions of these selections in advanced stages of infection.

Table 2 Antifungals for esophageal candidiasis

\begin{tabular}{llll}
\hline Antifungal agent & Form & Strength & Usage \\
\hline $\begin{array}{l}\text { Azoles } \\
\text { Ketoconazole }\end{array}$ & Tablets & $200 \mathrm{mg}$ & I-2 tablets, once to \\
& & & twice daily \\
Fluconazole & Tablet & 1 tablet daily & $10 \mathrm{~mL}$, once daily \\
& SolutionIV piggyback & $100 \mathrm{mg}$ & $100 \mathrm{mg}$, once daily \\
& & $10 \mathrm{mg} / \mathrm{mL}$ & 2 capsules, once daily \\
Itraconazole & Capsule & $100 \mathrm{mg}$ & $20 \mathrm{~mL}$, once daily \\
& Solution & $10 \mathrm{mg} / \mathrm{mL}$ & 4 tsp, twice daily \\
Posaconazole & Suspension & $100 \mathrm{mg} / 2.5 \mathrm{~mL}$ & Once daily \\
Voriconazole & Tablet/IV piggyback & $200 \mathrm{mg}$ & Once daily \\
Caspofungin & Intravenous & $50 \mathrm{mg}$ & Once daily \\
Micafungin & Intravenous & $150 \mathrm{mg}$ & Once daily \\
Anidulafungin & Intravenous & $50 \mathrm{mg}$ & Once daily \\
Amphotericin B & Intravenous & $0.3-0.7 \mathrm{mg} / \mathrm{kg}$ & \\
\hline
\end{tabular}


Classes of agents used in the treatment of MC in HIV includes the polyenes (eg, amphotericin B, nystatin), pyrimidine synthesis inhibitors (flucytosine), azoles (miconazole, clotrimazole, ketoconazole, itraconazole, fluconazole, voriconazole, posaconazole), and, more recently, the echinocandins (caspofungin, micafungin, anidulafungin). ${ }^{17,22,24} \mathrm{Common}$ dosage regimens of these agents are listed in Tables 1 and 2.

The key trials evaluating antifungals in the treatment of OPC and EC are summarized in Table 3. Most controlled studies to date have evaluated the azole antifungal agents and in general, clinical response rates appear to be similar. Clinical response varies widely, as does the rate of relapse. Studies of antifungal treatment in MC can be problematic to evaluate, particularly in the HIV-positive population. Limitations often include a small number of patients, open label design, and a short follow-up time. Additional studies are particularly needed among patients with low $\mathrm{CD}^{+} \mathrm{T}$ lymphocyte counts, as this population tends to have lower clinical and mycological response rates. A recent meta-analysis suggested that larger studies using more consistent outcome measures and reporting would be helpful in applying future research to current clinical practice. ${ }^{25}$ Additionally, these authors also suggested that future investigations should include less expensive antifungal interventions and, at the same time, evaluate symptom-free periods, quality of life, survival, and the development of clinical and in vitro resistance.

\section{Therapy of oropharyngeal candidiasis}

Prior to the development of the polyenes and the azoles, topical therapy consisted of gentian violet applications that were reasonably effective in localized MC, but were extremely messy because of the purple color. ${ }^{24,26}$

While topical therapies have historically been effective in less severe disease and are relatively inexpensive compared to some of the systemic therapies, their use has diminished

Table 3 Clinical trials of antifungal agents for the treatment of OPC and EC in HIV-positive patients

\begin{tabular}{|c|c|c|c|}
\hline Authors & $\begin{array}{l}\text { Regimens evaluated } \\
\text { ( } n=\text { number of subjects) }\end{array}$ & Clinical response & Relapse rate \\
\hline \multicolumn{4}{|c|}{ Oropharyngeal candidiasis (OPC) } \\
\hline \multirow[t]{2}{*}{ DeWit et $\mathrm{al}^{37}$} & Fluconazole 50 mg/day $(\mathrm{n}=17)$ & $100 \%$ & $46 \%$ at 30 days \\
\hline & Ketoconazole 200 mg/day $(n=16)$ & $75 \%$ & I I\% \\
\hline \multirow[t]{2}{*}{ Smith et al ${ }^{106}$} & Ketoconazole 200 mg BID $(n=40)$ & $93 \%$ & $>80 \%$ at 90 days \\
\hline & Itraconazole 200 mg/day $(n=46)$ & $93 \%$ & $>80 \%$ \\
\hline \multirow[t]{2}{*}{ Barchiesi et al ${ }^{107}$} & Fluconazole 200 mg/day $(\mathrm{n}=38)$ & $42 \%$ & $62 \%$ \\
\hline & Ketoconazole 400 mg/day $(n=39)$ & $34 \%$ & $22 \%$ \\
\hline \multirow[t]{2}{*}{ Pons et $\mathrm{al}^{30}$} & Fluconazole 100 mg/day $(n=152)$ & $98 \%$ & $34 \%$ at 42 days \\
\hline & Clotrimazole 10 mg 5/day $(n=136)$ & $48 \%$ & $40 \%$ \\
\hline \multirow[t]{2}{*}{ de Repentigny et al ${ }^{108}$} & Ketoconazole 200 mg/day $(n=52)$ & $60 \%$ & $80 \%$ at 60 days \\
\hline & Itraconazole 200 mg/day $(n=46)$ & $71 \%$ & $80 \%$ at 60 days \\
\hline \multirow[t]{5}{*}{ Vazquez et $a^{58}$} & Fluconazole 100 mg/day $(n=94)$ & $51 \%$ & $37 \%$ at 30 days \\
\hline & Posaconazole 50 mg/day $(n=98)$ & $74 \%$ & $41 \%$ \\
\hline & Posaconazole 100 mg/day $(n=102)$ & $80 \%$ & $38 \%$ \\
\hline & Posaconazole 200 mg/day $(\mathrm{n}=91)$ & $74 \%$ & $35 \%$ \\
\hline & Posaconazole $400 \mathrm{mg} /$ day $(\mathrm{n}=100)$ & $83 \%$ & $36 \%$ \\
\hline \multirow[t]{2}{*}{ Vazquez et $\mathrm{al}^{32}$} & Miconazole lauriad 10 mg/day $(\mathrm{n}=283)$ & $68 \%$ & $27 \%$ \\
\hline & Clotrimazole 10 mg 5/day $(n=28 \mathrm{I})$ & $74 \%$ & $28 \%$ \\
\hline \multicolumn{4}{|c|}{ Esophageal candidiasis (EC) } \\
\hline \multirow[t]{2}{*}{ Laine et $a^{66}$} & Ketoconazole $200 \mathrm{mg} /$ day $(\mathrm{n}=7 \mathrm{I})$ & $65 \%$ & N/A \\
\hline & Fluconazole 100 mg/day $(n=72)$ & $85 \%$ & \\
\hline \multirow[t]{2}{*}{ de Repentigny et al ${ }^{108}$} & Ketoconazole 200 mg/day $(n=19)$ & $100 \%$ & $58 \%$ at 60 days \\
\hline & Itraconazole 200 mg/day $(\mathrm{n}=12)$ & $65 \%$ & $82 \%$ at 60 days \\
\hline \multirow[t]{2}{*}{ Ally et $\mathrm{al}^{72}$} & Fluconazole 200 mg/day $(\mathrm{n}=|4|)$ & $90 \%$ & $\mathrm{~N} / \mathrm{A}$ \\
\hline & Voriconazole 200 mg BID $(n=1$ I5) & $95 \%$ & \\
\hline \multirow[t]{2}{*}{ Villaneueva et $\mathrm{al}^{77}$} & Fluconazole 200 mg/day $(n=94)$ & $89 \%$ & $17 \%$ at 28 days \\
\hline & Caspofungin 50 mg/day $(\mathrm{n}=8 \mathrm{I})$ & $90 \%$ & $28 \%$ at 28 days \\
\hline \multirow[t]{4}{*}{ de Wet et $\mathrm{al}^{78}$} & Fluconazole 200 mg/day $(n=60)$ & $80 \%$ & $\mathrm{~N} / \mathrm{A}$ \\
\hline & Micafungin 50 mg/day $(n=64)$ & $84 \%$ & \\
\hline & Micafungin 100 mg/day $(n=62)$ & $92 \%$ & \\
\hline & Micafungin 150 mg/day $(n=59)$ & $92 \%$ & \\
\hline \multirow[t]{2}{*}{ Krause et al ${ }^{79}$} & Fluconazole 400 mg/day $(n=255)$ & $99 \%$ & I I\% at 14 days \\
\hline & Anidulafungin $200 \mathrm{mg}$ then $100 \mathrm{mg} / \mathrm{day}(\mathrm{n}=249)$ & $99 \%$ & $36 \%$ \\
\hline
\end{tabular}


due to poor tolerability and poor adherence. Topical therapy of OPC can be accomplished with a multitude of antifungal agents including nystatin, amphotericin B, clotrimazole, and, more recently, miconazole (Table 1). ${ }^{17,22,24,26-31}$ Nystatin is available in several formulations, including pastilles and suspension. Limitations of topical agents such as nystatin include a bitter taste, GI-adverse effects, and frequent dosing, all of which may contribute to reduced adherence. ${ }^{24,27}$ Importantly, nystatin has not demonstrated significant efficacy in severely immunocompromised patients, such as those with advanced HIV infection. ${ }^{27,28}$ For instance, in HIV-positive patients, nystatin exhibited lower rates of both clinical cure (52\% vs $87 \%$ ) and mycological cure (6\% vs 60\%) when compared to oral fluconazole. Additionally, the 28- day relapse rate was found to be greater with nystatin (44\% vs $18 \%$ ) when compared to fluconazole. ${ }^{27}$

Amphotericin B is also an option for topical therapy and is available in suspension, lozenge, and tablet form. ${ }^{1,22}$ Neither nystatin, nor amphotericin B is absorbed from the gastrointestinal tract so administration must be frequent (four times daily) to provide adequate drug exposure to the infected mucosal tissues. ${ }^{1,22}$ Prospective, comparative studies evaluating amphotericin B oral solution against other antifungals are limited. Topical azole antifungal agents, such as clotrimazole $10 \mathrm{mg}$ troches, administered five times daily, provide another option for OPC patients. Topical clotrimazole has been used successfully in treating mild-to-moderate OPC during the early stages of HIV disease. ${ }^{28-30}$

The newest topical antifungal is the mucoadhesive buccal tablet (MMBT) containing $50 \mathrm{mg}$ of miconazole (Loramyc ${ }^{\circledR}$ ). ${ }^{31}$ This novel formulation of miconazole has been approved in Europe since 2008 for the treatment of OPC in immucocompromised hosts. The formulation is unique, because $50 \mathrm{mg}$ of miconazole is contained in each mucoadhesive tablet and is applied to the mucosa of the upper gum over the canine fossa, once daily, for 7-14 days. The MMBT adheres to the gum surface because of the milk protein concentrate composition of the tablet. This interaction leads to a rapid and prolonged adhesion to the mucosa due to an adsorption mechanism, followed by a protein-protein interaction. In pharmacokinetic studies, $50 \mathrm{mg}$ of MMBT provides a maximum salivary concentration of $15 \mu \mathrm{g} / \mathrm{mL}$, up to seven hours after the application of the tablet. ${ }^{31}$ Three separate clinical studies have evaluated the use of MMBTs for the treatment of OPC in the HIV-positive population and in patients with head and neck cancers. ${ }^{32-34}$ In a phase III, double-blind, double-dummy, multicenter trial evaluating 578 patients with HIV and OPC, MMBT treatment was compared to clotrimazole troches $(10 \mathrm{mg}$, five times daily, for a period of 14 days). ${ }^{32}$ The results at the primary endpoint of test of cure (TOC) in both the intent-to-treat (ITT) population and in the per-protocol population (PP) demonstrated that the once daily administration of a MMBT was as effective as the five times daily clotrimazole treatment. Clinical cure rates at TOC in both the ITT (61\% vs 65\%) and PP (68\% vs $74 \%$ ) populations demonstrated no inferiority to clotrimazole. In addition, secondary endpoints such as safety and tolerability were similar between both treatment groups.

The use of topical antimycotic agents has been replaced with systemic azole antifungals such as ketoconazole, fluconazole, itraconazole, and more recently posaconazole (Table 1). ${ }^{17,24}$ Part of the reason for this is that, although clinical cure rates may be similar, microbiologic cure and long term efficacy are not. In one example, a study comparing systemic oral fluconazole with clotrimazole troches in HIV-positive adults found clinical efficacy to be similar (98\% vs 94\%). However, microbiological cure rates were greater in patients treated with fluconazole (65\% vs 48\%) and clinical response sustained through a 2 -week follow up was also greater ( $82 \%$ vs $50 \%){ }^{30}$

The currently available systemic azoles include ketoconazole, fluconazole, itraconazole, and posaconazole. Ketoconazole was the first available oral systemic imidazole antifungal agent with high rates of efficacy in OPC. ${ }^{35,36}$ However, in comparative trials, ketoconazole was found to be less efficacious then fluconazole in both clinical and mycological cure rates. ${ }^{37}$ In addition, the use of ketoconazole is further limited by potentially severe adverse reactions including hepatotoxicity, poor oral bioavailability, and a host of drug-drug interactions. ${ }^{36}$ Ketoconazole is a very potent inhibitor of cytochrome P450 3A4 and is relatively contraindicated with some HIV-protease inhibitors. ${ }^{38}$ Because the drug's absorption is dependent upon an acidic $\mathrm{pH}$, there are also concerns that systemic absorption may be inadequate in patients receiving acid-suppressive therapy or with AIDS-related hypochlorhydria. ${ }^{39}$ In view of the lower clinical efficacy rates and the associated adverse event profile (ie, hepatotoxicity), ketoconazole is not widely used anymore. In contrast to ketoconazole, other azoles such as fluconazole, itraconazole, voriconazole, and posaconazole have demonstrated improved efficacy, as well as excellent safety profiles, and have thus become the drugs of choice for OPC, especially in HIV-positive patients (Table 3). ${ }^{1,22,24,30}$

Fluconazole is the most commonly used antifungal in the treatment of MC in HIV-infected patients. It is available in oral suspension, tablet, and parenteral formulations. Fluconazole is more readily absorbed than other oral azoles without being affected by either food or gastric acidity. The clinical 
efficacy of fluconazole has been established in many well controlled clinical trials, such that it has become the standard comparator in clinical trials of novel agents. ${ }^{24,30,37,40-42}$ Most studies of fluconazole have used an initial loading dose of $200 \mathrm{mg}$ followed by $100 \mathrm{mg}$ daily, but clinical success has been achieved with doses as low as $50 \mathrm{mg} /$ day. ${ }^{40}$ Clinical response is usually apparent within 10 days with $50 \mathrm{mg} /$ day, and 5 to 7 days for doses of 100-200 mg/day. ${ }^{17,40}$ Of the available azoles, fluconazole is associated with the fewest drug-drug interactions because it has less affinity for the CYP3A4 enzyme. ${ }^{38,43}$ The pharmacological interactions with fluconazole include concomitantly administered phenytoin, rifampin, rifabutin, cyclosporin A, and possibly some of the protease inhibitors. ${ }^{38,39,43-45}$ Fluconazole is generally well tolerated, however, as with any other azole being used long term, periodic surveillance of liver enzymes to monitor for hepatotoxicity is useful. ${ }^{24,43}$

Itraconazole is supplied in a cyclodextrin oral solution or capsule; the parenteral formulation is no longer manufactured in the United States. ${ }^{1,24,46}$ Like ketoconazole, itraconazole exhibits a strong potential for drug-drug interactions through the CPY3A4 enzyme system. ${ }^{38,46,47}$ The itraconazole oral solution has greater bioavailability than the capsule and absorption is further enhanced by postprandial administration. ${ }^{40,46-48}$ One prospective, randomized trial in HIV-positive and AIDS patients with OPC, found itraconazole oral solution to have similar efficacy and safety as fluconazole (clinical response $97 \%$ vs $87 \%) .{ }^{49}$ However, approximately $50 \%$ of the patients in both groups experienced relapses at the 1-month follow-up evaluation.

Posaconazole is the newest triazole on the market and is approved for the treatment of acute OPC and antifungalrefractory MC. ${ }^{50-52}$ It is an oral extended-spectrum triazole with potent in vitro activity against pathogenic yeast and moulds, including fluconazole- and itraconazole-resistant Candida strains. ${ }^{50}$ As with other azoles, posaconazole inhibits lanosterol $14-\alpha$-demehylase. It appears that mutations near the heme cofactor of CYP51 reduce the binding affinity of compact azoles, such as fluconazole and itraconazole, and may lead to azole crossresistance. ${ }^{50}$ However, 3-dimensional binding models suggest that the long side chain of posaconazole may result in tighter binding affinity. ${ }^{53,54}$ Thus, posaconazole may be less susceptible than some azoles to the development of secondary azole resistance. Posaconazole is absorbed in an oral suspension. ${ }^{50}$ It is important to note that posaconazole absorption is enhanced by coadministration with food, especially high fatty meals, or with a nutritional supplement such as Boost ${ }^{\circledR}$ Plus (Nestlé, Fremont, MI). ${ }^{55,56}$
When food intake is limited, dividing the daily dose from BID (twice daily) to QID (four times daily) also increases the plasma concentration. Unlike itraconazole and voriconazole, posaconazole is not primarily metabolized by fungal cytochrome P450 enzymes. ${ }^{57}$ During several drug interaction trials evaluating the effects of posaconazole on the CYP450 enzymes, posaconazole did demonstrate an inhibitory effect on CYP3A4, but did not influence the other isoenzymes. In a large multicenter, randomized clinical trial, a $100 \mathrm{mg}$ daily dose of posaconazole was compared to a $100 \mathrm{mg}$ daily dose of fluconazole in HIV-positive patients with OPC..$^{58}$ Clinical success was reported in $92 \%$ of the posaconazole recipients compared with a success rate of $92 \%$ for those patients that received fluconazole. The only difference was in the long-term follow-up, where clinical relapses occurred more frequently in the fluconazole group compared to the posaconazole group $(38.2 \%$ vs $31.5 \%)$. In general, the adverse events reported in both groups were comparable.

Several concerns have been raised about the widespread use of the more potent oral azoles, which may offer only minor advantages for patients. These concerns include drug interactions, side effects, increased expense, and risk of developing antifungal resistance. An increased frequency of C. glabrata isolation has been described by several investigators of HIV-positive patients receiving prolonged courses of fluconazole. ${ }^{59-62}$ In addition, although azole resistance in C. albicans is rare, several reports describe both clinical failure and in vitro resistance in both non-HIV patients and in HIV-infected patients on long-term azoles. ${ }^{24,63}$

\section{Therapy of esophageal candidiasis}

Systemic antifungal therapy using oral or parenteral fluconazole has been the mainstay in the management of EC for over a two decades (Tables 2 and 3). ${ }^{1,17}$ Topical antifungals such as nystatin, clotrimazole, and miconazole are of minimal value in EC. ${ }^{22,64}$ The initial step in the management of EC should always be to attempt to minimize all possible predisposing factors, such as corticosteroids, chemotherapeutic agents, and antimicrobials. ${ }^{1,17,22}$

Oral fluconazole has an excellent safety profile when compared to ketoconazole, demonstrates excellent gastric absorption, and can also be given intravenously when necessary. Similar to the observations in OPC research, studies comparing fluconazole with either clotrimazole or ketoconazole for $\mathrm{CE}$ demonstrate cure rates that are superior to those with other imidazoles. Moreover, fluconazole demonstrated a more rapid onset of action and quicker resolution of symptoms ${ }^{65-67}$ Itraconazole has also been shown to be effective in 
the treatment of EC. ${ }^{68-70}$ Patients treated with itraconazole oral solution (100-200 mg/day) had clinical response rates comparable to those of patients treated with fluconazole tablets (100-200 mg/day) of 94\% and 91\%, respectively, without significant adverse effects in either group. ${ }^{68}$ The mycological cure rates were also similar at $92 \%$ and $78 \%$, respectively.

Voriconazole, another broad spectrum systemic triazole is also approved for the treatment of EC at a dose of $200 \mathrm{mg}$ BID for 14-21 days. In vitro, it has been shown to be 10 - to 500-fold more potent than fluconazole against a wide array of yeast and moulds, including many isolates that have demonstrated in vitro itraconazole- and/or fluconazoleresistance. ${ }^{71}$ In a double-blind, randomized, multicenter study, voriconazole $200 \mathrm{mg}$ BID was compared to fluconazole $200 \mathrm{mg}$ daily in EC. ${ }^{72}$ The overall success rates were comparable at $98.2 \%$ for voriconazole vs $95 \%$ for fluconazole. Furthermore, the overall safety and adverse event profile of both agents was comparable. As with most azoles, voriconazole has an effect on the CYP450 enzymes, so caution regarding drug-drug interactions is warranted. ${ }^{36,71} \mathrm{~A}$ common side effect with voriconazole includes photopsia (visual abnormalities) that may occur in $20 \%-30 \%$ of patients. These abnormalities eventually resolve after 3-4 days of continued usage. Other side effects may include elevations in transaminases $(\sim 10 \%)$ and skin rashes $(\sim 10 \%)$, with rare cases of photodermatitis in patients who are exposed to direct sunlight. ${ }^{71}$

Prior to the availability of azole antifungal agents, amphotericin B deoxycholate was used extensively. However, it is now rarely used in any patient and is generally reserved for antifungal-refractory cases of Candida esophagitis that do not respond to azoles or echinocandins. ${ }^{73}$ If necessary, low dose amphotericin B (0.15-0.3 mg/kg/day or $10-20 \mathrm{mg} /$ day for 10-14 days) is sufficient for moderate to severe disease..$^{1,17,73}$ However, because of the improved adverse event profiles of the lipid formulations of amphotericin B, they have also become popular. Oral flucytosine (100-150 mg/kg/day in divided doses), although effective, is rarely used because of the tendency for resistance to develop during therapy and the well described frequency of bone marrow suppression and transaminase elevation. ${ }^{1,74}$ Furthermore, in one comparative clinical trial, clinical efficacy and mycological cure rates were lower for flucytosine when compared to fluconazole. ${ }^{74}$

The echinocandin class of antifungals, which includes caspofungin, micafungin, and anidulafungin are a novel class of antifungal agents with a completely different mechanism of action. ${ }^{75}$ All three agents have demonstrated excellent in vitro activity against a broad array of Candida species, including those that are resistant to fluconazole, itraconazole, or voriconazole. ${ }^{75}$ There have been a total of five clinical trials evaluating the efficacy of the three echinocandins in treating EC in HIV-positive patients. In all studies, the echinocandins are compared to either fluconazole or amphotericin $\mathrm{B}$. In a clinical trial comparing caspofungin to amphotericin B in both OPC and EC in a population that was predominantly HIV-positive, clinical success rates for caspofungin ranged from $74 \%$ to $91 \%$, which was numerically greater than the success rate for amphotericin B $(63 \%){ }^{76}$ In a related study, 177 patients with EC were stratified to receive either fluconazole $200 \mathrm{mg} /$ day or caspofungin $50 \mathrm{mg} /$ day. Caspofungin was found to have similar response and relapse rates as fluconazole. ${ }^{77}$ In another clinical trial, the treatment of EC among HIV-positive patients was also found to be similar for micafungin $150 \mathrm{mg}$ /day when compared to fluconazole $200 \mathrm{mg} /$ day. ${ }^{78}$ In a separate multicenter clinical study in HIV-positive patients ( $n=601,75 \%$ with AIDS) evaluating anidulafungin versus fluconazole in patients with EC found this echinocandin to have similar clinical response rates when compared to fluconazole, in terms of both efficacy and safety. ${ }^{79}$ So, while the echinocandins are not considered first line therapy for EC, they are effective antifungals for the treatment of MC in HIV-positive patients. Their use however, is limited because of the lack of an oral formulation.

Clinical relapse is not uncommon, especially in patients with persistent underlying immunodeficiency (eg, untreated and advanced HIV infection). Relapse appears to depend on the duration of antifungal therapy and degree of immunosuppression and may occur sooner following clotrimazole and ketoconazole therapy than after itraconazole, fluconazole, or posaconazole therapy. ${ }^{30,71,80,81}$ After several recurrences of symptomatic OPC in patients with AIDS, clinicians may consider maintenance (secondary) prophylaxis. ${ }^{80}$

Several dosages of fluconazole as the primary prophylaxis have been evaluated. Although most studies documented a reduction in the frequency of $\mathrm{MC}$ in treated patients with AIDS, the regimens did not provide complete protection and occasional breakthrough infections occurred. ${ }^{82,84}$ Powderly et al compared fluconazole $200 \mathrm{mg} /$ day and clotrimazole troches $10 \mathrm{mg}$ five-times/day prophylactically in HIV-positive patients. ${ }^{83}$ Overall, fluconazole reduced the frequency of $\mathrm{MC}$, superficial fungal infections, and cryptococcal disease when compared to clotrimazole. ${ }^{83}$ The benefit was greatest in patients with less than $50 \mathrm{CD}^{+} \mathrm{T}$ cells $/ \mathrm{mm}^{3}$. Unfortunately, in this study, the incidence of in vitro resistance and the effect fluconazole had on fungal flora was not evaluated. In addition, although the incidence of fungal infections was 
reduced, the survival rate was similar in both groups. In this setting, one must weigh the benefits against the cost of daily drug administration, not only in the financial sense, but also the influence of the agent on the patient's mycoflora.

Schuman et al evaluated fluconazole $200 \mathrm{mg} /$ week vs placebo in HIV-infected women with $\mathrm{CD}^{+} \mathrm{T}$ cell counts $<300$ cells $/ \mathrm{mm}^{85}$ The study concluded that weekly fluconazole was effective in preventing symptomatic OPC and vaginal candidiasis while the rates of clinical and in vitro resistance were low. Additionally, women receiving fluconazole had a reduction in the colonization rates of $C$. albicans, but had an increased isolation of non-albicans Candida species. In a recent multicenter, randomized clinical trial evaluating the role of prophylaxis in HIV-positive patients, Goldman et al showed that the number of episodes of OPC and other invasive fungal infections was statistically lower in HIV-positive patients with $\mathrm{CD}^{+} \mathrm{T}$ counts $<150$ cells $/ \mathrm{mm}^{3}$, when receiving continuous (three times a week fluconazole) when compared to those patients only receiving episodic treatment with fluconazole for OPC recurrences. ${ }^{84}$ The study also demonstrated that the incidence of clinically significant resistance was no higher in the group receiving continuous therapy than in the group using episodic administration of fluconazole, provided the patients were on highly active antiretroviral therapy.

In general, when making the clinical decision to initiate secondary prophylaxis the physician should consider several key points: the impact of excessive recurrences on the patients well being and quality of life, the need for prophylaxis of other fungal infections, financial costs, adverse event profiles, and drug-drug interactions.

\section{Management of antifungal-refractory mucosal candidiasis}

The clinical impact of antifungal resistance in patients with AIDS has been demonstrated in patients who failed conventional antifungal therapy for MC. ${ }^{24,86}$ After the development of fluconazole-resistant OPC, patients were noted to have a median survival of approximately 184 days. Moreover, after the onset of clinical resistance to parenteral amphotericin $\mathrm{B}$, patients were found to have an astonishing 83 -day median survival rate. ${ }^{24,86}$ Although MC per se is not fatal, clinical failure is probably a comorbid factor associated with the rapid demise of these patients. Clinical failure may also be a marker of severe immunosuppression and a dysfunctional immune system.

Antifungal resistance can be divided into two categories, clinical and in vitro. Clinical resistance signifies failure of the antifungal to eradicate the infection in the absence of in vitro resistance. Such resistance may occur for a variety of reasons. In vitro resistance can also be subdivided into either primary (innate or intrinsic ) or secondary (acquired) resistance. $^{24,86}$

The usefulness of bacterial in vitro susceptibility testing is well established in the management of patients with infectious diseases. However, despite the fact that a subcommittee for in vitro antifungal susceptibility testing published approved guidelines, the utility of these results in managing fungal infections is still somewhat controversial. ${ }^{87,88}$ Several studies have revealed a correlation between the in vitro susceptibility minimum inhibitory concentration [MIC] results of $C$. albicans and the clinical response to antifungal treatment in HIV-infected patients. ${ }^{60,87,88}$ Investigators have published therapeutic antifungal successes and failures in patients with OPC and Candida isolates for which MICs were both low and high. In fact, one group has reported several HIV-infected patients with documented in vitro fluconazole-resistant MC who were still able to respond to fluconazole therapy.

Initially, it was believed that the trigger for the emergence of resistance was primarily due to the use of low dose fluconazole for acute treatment as well as for prophylaxis. ${ }^{86,89,90}$ More recently, investigators have demonstrated that $\mathrm{MC}$ due to resistant isolates is seen in patients with low $\mathrm{CD}^{+}$ cell counts $\left(<50\right.$ cells $\left./ \mathrm{mm}^{3}\right) .{ }^{91}$ Conversely, another study indicated that a low $\mathrm{CD}^{+}$cell count did not predict azoleresistant $\mathrm{MC}$ in patients with AIDS. ${ }^{61}$

Investigators have be able to identify several key risk factors associated with the development of fluconazole-resistant MC in patients with AIDS, compared to those patients without evidence of fluconazole-resistant MC. These risk factors include: greater number of episodes of OPC (6.1 vs 1.8), lower median $\mathrm{CD}^{+}$cell count ( 11 vs 71 cells $/ \mathrm{mm}^{3}$ ), longer median duration of antifungal therapy (419 vs 118 days), and longer duration of systemic azoles (272 vs 14 days). ${ }^{91}$ When the authors used two controls matched by $\mathrm{CD}^{+}$cell count, resistant cases continued to have a greater median exposure time to azoles (272 vs 88 days; $P=0.005$ ) as the significant risk factor. ${ }^{61,91}$

It is still not clear whether the total dose of antifungals, the duration of therapy, the type of antifungal, and/or the pattern of drug administration (continuous vs episodic) are the most important determinants in the development of antifungal-refractory fungal disease..$^{24,84,90,91}$ More than likely, the etiology is multifactorial involving a combination of advanced immunosuppression, high fungal burdens, and prolonged exposure time to antifungals.

The management of fluconazole-resistant $\mathrm{MC}$ is frequently unsatisfactory and the clinical response is short-lived 
with periodic and rapid recurrences. In some patients, the refractory candidiasis may respond to increases in the dose of fluconazole (Table 4). For example, if patients fail fluconazole $200 \mathrm{mg} /$ day, a dosage increase to $400-800 \mathrm{mg} /$ day will frequently produce a clinical response for a period of time. However, the response is generally transient and the disease recurs rapidly once patients have reached this stage. As noted, clinical and in vitro azole resistance is not uncommon in patients who fail to respond to fluconazole. Occasionally, in some patients with fluconazole-refractory $\mathrm{MC}$, fluconazole suspension may be beneficial. ${ }^{91}$ Several reports describe improvement in these patients, possibly associated with increased salivary levels of fluconazole, which results when the suspension is taken with a swish-and-swallow technique. ${ }^{91}$

Several clinical trials evaluating itraconazole oral solution have demonstrated promising results in patients with AIDS who failed fluconazole $200 \mathrm{mg} /$ day ${ }^{92-95}$ A clinical cure or improvement occurred in $55 \%-70 \%$ of these patients. As expected, mycological cure rates were low $(<30 \%)$ and relapses following treatment cessation were rapid, usually within 14 days.

The two newly expanded spectrum triazoles, voriconazole and posaconazole, have been used successfully in patients with refractory MC. ${ }^{96,97}$ Posaconazole is licensed in the United States for the treatment of refractory OPC/EC. In the largest clinical trial evaluating antifungal agents for refractory $\mathrm{OPC} / \mathrm{EC}$,

Table 4 Alternative therapies for the management of antifungalrefractory mucosal candidiasis in patients with AIDS

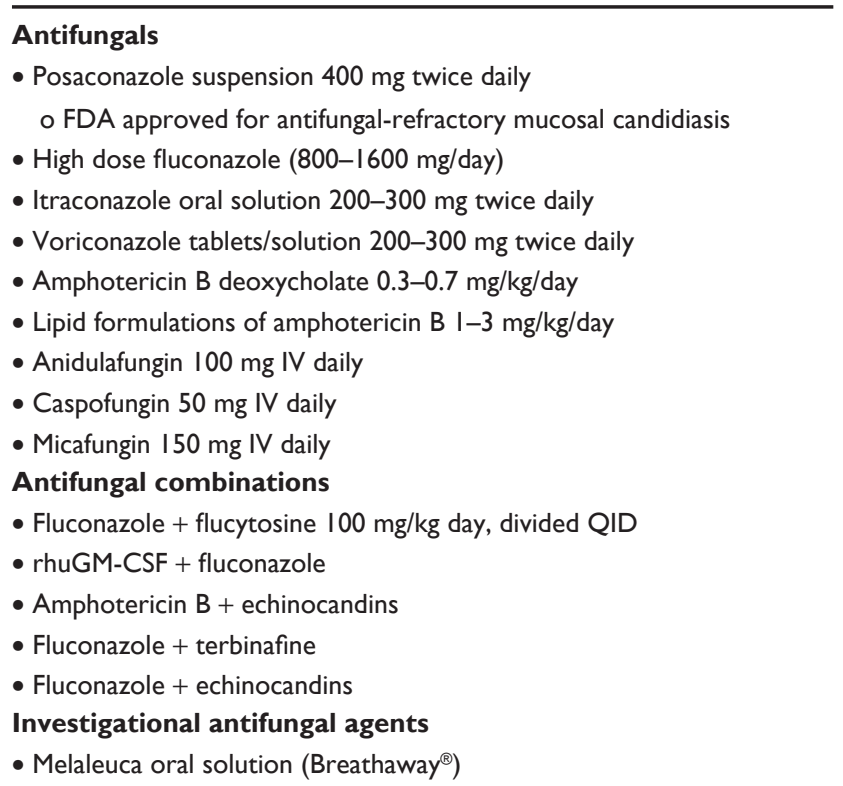

Note: Many of the alternative therapies are not FDA approved and not supported by adequate clinical trials.

Abbreviations: FDA, US Food and Drug Administration; rhuGM-CSF, recombinant human granulocyte-macrophage colony-stimulating factor; QID, four times daily. posaconazole $400 \mathrm{mg}$ suspension was given either QD (once daily) or BID and was evaluated in subjects with documented clinical resistance to either fluconazole or itraconazole. ${ }^{96}$ Of the 176 subjects enrolled, 132 (75\%) achieved a clinical response after 28 days of therapy with very few adverse events. Only eight patients discontinued the study drug because of a side effect. As expected, during the 4-week follow up period the overall clinical relapse rate was $74 \%$.

It is important to note that with any fungal infection in patients with advanced HIV infection it is essential to continue suppressive antifungal therapy in an attempt to increase disease-free intervals and avoid morbidity and occasional mortality. These patients generally suffer from advanced-HIV disease and ultimately very low $\mathrm{CD}^{+} \mathrm{T}$ cells $(<50)$ and high viral burdens along with uncontrolled HIV infection. ${ }^{81}$

It is important not to underestimate the significance of the underlying dysfunctional immune system in patients with AIDS and refractory fungal infections. Although randomized clinical trials have not been done, the initiation of HAART will frequently assist in the resolution of these recalcitrant infections. In fact, treatment with HAART alone without antifungals have eradicated antifungal-refractory OPC in patients with advanced HIV infection..$^{98,99}$

The classic management of infections in the compromised host has depended upon antimicrobial agents, without taking into account host defects. Several cytokines developed and produced by recombinant technology show promise in assisting the host response to fungal infection. ${ }^{100,101}$ There have been several reports describing the use of human recombinant granulocyte-macrophage colony stimulating factor (rhuGM$\mathrm{CSF}$ ) in patients with OPC or EC refractory to fluconazole and amphotericin B. ${ }^{100,101}$ Although no large studies have been published, case reports describe good response rates with rhuGM-CSF in patients with advanced HIV infection and refractory mucosal candidiasis. ${ }^{101,102}$ Further studies evaluating these cytokines are certainly warranted.

Alternative therapeutic modalities using organic substances are also being administered empirically to combat refractory MC. One of these formulations is Melaleuca alternafolia, or Australian tea tree oil that has been formulated into an oral solution. A small, single center pilot study evaluating the melaleuca oral solution in 14 patients with AIDS and fluconazole-refractory OPC has been completed. ${ }^{103}$ The results appear to indicate relatively good efficacy in these difficult-to-treat patients, demonstrating a good clinical response in 10 of 12 patients after four weeks of antifungal therapy. However, larger comparative studies are necessary to evaluate the role of this agent in refractory candidiasis. 
In conclusion, significant advances in antifungal therapy have been made in the last decade. The impressive clinical trial results and the low grade side effect profile of the azole compounds continue to make them attractive choices in the management of fungal infections in any immunocompromised patient, especially HIV-positive patients. However, difficulties in managing these infections should remind us that we can not rely solely on antifungals. We must continue to find ways to improve the body's dysfunctional immune system. In addition, we must continue to develop more effective antifungal agents with different mechanisms of action and different modes of administration.

\section{Disclosure}

The author reports no conflict of interest in this work.

\section{References}

1. Vazquez JA, Sobel JD.Candidiasis. In: Dismukes WE, Pappas PG, Sobel JD, editors. Clinical Mycology. Oxford: Oxford University Press; 2003:143-187.

2. Kleinegger CL, Lockhart SR, Vargas K, Soll DR. Frequency, intensity, species, and strains of oral Candida vary as a function of host age. J Clin Microbiol. 1996;34:2246-2254.

3. Johnston RD, Chick EW, Johnston NS, Jarvis MA. Asymptomatic quantitative increase of Candida albicans in the oral cavity: predisposing conditions. South Med J. 1967;60:1244-1247.

4. Stenderup A, Pedusen GT. Yeast of human origin. Acta Pathol Microbiol Scand. 1962;54:462-472.

5. Mackenzie DWR. Yeast from human sources. Sabouraudia. 1962;1:8-15

6. van't Wout JW. Fluconazole treatment of candidal infections caused by non-albicans Candida species. Eur J Clin Microbiol Infect Dis. 1996;15:238-242.

7. Barchiesi F, Morbiducci V, Ancarani F, Scalise G. Emergence of oropharyngeal candidiasis caused by non-albicans species of Candida in HIV-infected patients. Eur J Epidemiol. 1993;9:455-456.

8. Cunha Villar C, Dongari-Bagtzoglou A. Immune defence mechanisms and immunoenhancement strategies in oropharyngeal candidiasis. Expert Rev Mol Med. 2008;10(e29):1-18.

9. Chandler FW. Pathology of the mycoses in patients with the acquired immune deficiency syndrome (AIDS). Curr Topics Med Mycol. 1985;1:1-23.

10. Melbye M, Schonheyder H, Kesters L, et al. Carriage of oral Candida albicans associated with a high number of circulating suppressor $\mathrm{T}$ lymphocytes. [Letter] J Infect Dis. 1985;152:1356-1357.

11. Kalo-Klein A, Witkin SS. Prostaglandin $\mathrm{E}_{2}$ enhances and gamma interferon inhibits germ tube formation in Candida albicans. Infect Immunity. 1990;58:260-262.

12. Fidel PL, Lilly E, Rufener JB, et al. Longitudinal analysis of local immune function in $\mathrm{HIV}(+)$ subjects with oropharyngeal candidiasis. In: Program and Abstracts of the 49th Annual Interscience Conference on Antimicrobial Agents and Chemotherapy, San Francisco, CA 2009 September 12-15, Abstract\# M-365.

13. de Repentigny L, Lewandowski D, Jolicoeur P. Immunopathogenesis of oropharyngeal candidiasis in human immunodeficiency virus infection. Clin Microbiol Reviews. 2004;17:729-759.

14. Silverman S Jr, Gallo JW, McKnight ML, Mayer P, deSanz S, Tan MM. Clinical characteristics and management responses in 85 HIV-infected patients with oral candidiasis. Oral Surg Oral Med Oral Pathol Oral Radiol Endod. 1996;82:402-407.
15. Feigal DW, Katz MH, Greenspan D, et al. The prevalence of oral lesions in HIV-infected homosexual and bisexual men: three San Francisco epidemiological cohorts. AIDS. 1991;5:519-525.

16. Powderly WG, Robinson K, Keath EJ. Molecular typing of Candida albicans isolated from oral lesions of HIV-infected individuals. AIDS. 1992;6:81-84.

17. Darouiche RO. Oropharyngeal and esophageal candidiasis in immunocompromised patients: treatment issues. Clin Infect Dis. 1998;26:259-274.

18. Selik RM, Starcher ET, Curran JW. Opportunistic diseases reported in AIDS patients: frequencies, associations, and trends. AIDS. 1987; $1: 175-182$.

19. Clotet B, Grifol M, Parro B, et al. Asymptomatic esophageal candidiasis in acquired-immunodeficiency-syndrome-related complex. [Letter] Ann Intern Med. 1986;105:145

20. Kodsi BE, Wickremesinghe PC, Kozinn PJ, Iswara K, Goldberg PK. Candida esophagitis: a prospective study of 27 cases. Gastroenterology. 1976;71:715-719.

21. Scott BB, Jenkins D. Gastro-oesophageal candidiasis. Gut. 1982;23:137-139.

22. Centers for Disease Control, National Institutes of Health, and the HIV Medicine Association of the Infectious Diseases Society of America. Guidelines for prevention and treatment of opportunistic infections in HIV-infected adults and adolescents. MMWR. 2009 March 28; Vol 58.

23. Glatt AE, Chirgwin K, Landesman SH. Treatment of infections associated with human immunodeficiency virus. $N$ Engl J Med. 1988;318:1439-1448.

24. Vazquez JA. Diagnosing and managing oropharyngeal candidiasis. Infect in Med. 2007;24:427-436.

25. Pienaar ED, Young T, Holmes H. Interventions for the prevention and management of oropharyngeal candidiasis associated with HIV infection in adults and children. Cochrane Database of Syst Rev. 2006: Issue 1.

26. Kozinn PJ, Taschdjian CL, Dragutsky D, et al. Therapy of oral thrush: a comparative evaluation of gentian violet, mycostatin and amphotericin B. Monogr Ther. 1957;2:16-24.

27. Pons V, Greenspan D, Lozada-Nur F, et al. Oropharyngeal candidiasis in patients with AIDS: randomized comparison of fluconazole versus nystatin oral suspensions. Clin Infect Dis. 1997;24:1204-1207.

28. Quintiliani R, Owens NJ, Quercia RA, Klimek JJ, Nightingale CH. Treatment and prevention of oropharyngeal candidiasis. Am J Med. 1994;77 Suppl 4D:44-48.

29. Shectman LB, Funaro L, Robin T, Bottone EJ, Cuttner J. Clotrimazole treatment of oral candidiasis in patients with neoplastic disease. Am J Med. 1984;76:91-94.

30. Pons V, Greenspan D, Debruin M, et al. Therapy for oropharyngeal candidiasis in HIV-infected patients: a randomized, prospective multicenter study of oral fluconazole versus clotrimazole troches. J Acquir Immune Defic Syndr. 1993;6:1311-1316.

31. Cardot JM, Chaumont C, Dubray C, Costantini D, Aiache JM. Comparison of the pharmacokinetics of miconazole after administration via a bioadhesive slow release tablet and an oral gel to healthy male and female subjects. Br J Clin Pharmacol. 2004;58:345-351.

32. Vazquez JA, Epstein J, Attali P. A multicenter, randomized trial evaluating the efficacy and safety of miconazole mucoadhesive buccal tablets (MMBT) versus clotrimazole troches (CT) for the treatment of oropharyngeal candidiasis (OPC) in subjects with HIV/AIDS:SMiLES Trial. In: Program and Abstracts of the 49th Annual Interscience Conference on Antimicrobial Agents and Chemotherapy, San Francisco, CA, 2009 September 12-15, Abstract\# M-1245.

33. Attali P, Vazquez J, Bensadoun RJ, Dupont B. Evaluation of miconazole mucoadhesive buccal tablet: a novel, once daily, antifungal regimen for the treatment of oropharyngeal candidiasis. 44th American Society of Health System Pharmacist Mid-Year Clinical Meeting and exhibition, The Venetian Hotel, Las Vegas, NV, 2009 Dec 6-10, Abstract 6-068. 
34. Bensadoun RJ, Daoud J, El Gueddari R, et al. Comparison of the efficacy and safety of miconazole 50-mg mucoadhesive buccal tablets with miconazole 500-mg gel in the treatment of oropharyngeal candidiasis. Cancer. 2008;112:204-211.

35. Hughes WT, Bartley DL, Patterson GG, Tufenkeji H. Ketoconazole and candidiasis: a controlled study. J Infect Dis. 1983;147:1060-1063.

36. Como JA, Dismukes WE. Oral azole drugs as systemic antifungal therapy. N Eng J Med. 1994;330:263-272.

37. DeWit S, Weerts D, Goossens H, Clumeck N. Comparison of fluconazole and ketoconazole for oropharyngeal candidiasis in AIDS. Lancet. 1989;1:746-748.

38. Meyer JM, Rodvold KA. Drug biotransformation by the cytochrome P-450 enzyme system. Infect Med. 1996;6:452-464.

39. Piscitelli SC, Flexner C, Minor JR, Polis MA, Masur H. Drug interactions in patients infected with human immunodeficiency virus. Clin Infect Dis. 1996;23:685-693.

40. Hay RJ. Overview of studies of fluconazole in oropharyngeal candidiasis. Rev Infect Dis. 1990;12 Suppl 3:S334-S337.

41. Meunier F, Aoun M, Gerard M. Therapy of oropharyngeal candidiasis in the immunocompromised host: a randomized double-blind study of fluconazole vs ketoconazole. Rev Infect Dis. 1990;12 Suppl 3: S364-S368.

42. Koletar SL, Russell JA, Fass RJ, Plouffe JF. Comparison of oral fluconazole and clotrimazole troches as treatment for oral candidiasis in patients infected with human immunodeficiency virus. Antimicrob Agents Chemother. 1990;34:2267-2268.

43. Kowalsky SF, Dixon DM. Fluconazole: a new antifungal agent. Clin Pharm. 1991;10:179-194.

44. Zimmermann T, Yeates RA, Laufen H, Pfaff G, Wildfeuer A. Influence of concomitant food intake on the oral absorption of two triazole antifungal agents, itraconazole and fluconazole. Eur J Clin Pharmacol. 1994;46:147-150.

45. Tucker RM, Denning DW, Hanson LH, et al. Interactions of azoles with rifampin, phenytoin, and carbamazepine: in vitro and clinical observations. Clin Infect Dis. 1992;14:165-174.

46. Van de Velde VJS, Van Peer AP, Heykants JJP, et al. Effect of food on the pharmacokinetics of a new hydroxypropyl- $\beta$-cyclodextrin formulation of itraconazole. Pharmacotherapy. 1996;16:424-428.

47. Data on File. Janssen Pharmaceutica, Beerse, Belgium.

48. Barone JA, Moskovitz BL, Guarnieri J, Hassell AE. Enhanced bioavailability of itraconazole in hydroxypropyl- $\beta$-cyclodextrin solution compared with capsules in healthy volunteers. Antimicrob Agents Chemother. 1998;42:1862-1865.

49. Graybill JR, Vazquez J, Darouiche RO, et al. Itraconazole oral solution: a novel and effective treatment for oropharyngeal candidiasis in HIV/ AIDS patients. Am J Med. 1998;104:33-39.

50. Herbrecht R. Posaconazole: a potent extended spectrum triazole antifungal for the treatment of serious fungal infections. Int J Clin Practice. 2004;58:612-624.

51. Vazquez JA. Posaconazole for the management of mucosal candidiasis. Future Microbiol. 2007;2:245-256.

52. Vazquez JA. Role of posaconazole in the management of oropharyngeal and esophageal candidiasis. Therap Clin Risk Management. 2007;3:533-542.

53. Li X, Brown N, Chau AS, et al. Changes in susceptibility to posaconazole in clinical isolates of Candida albicans. J Antimicrob Chemother. 2004;53:74-80.

54. Xiao L, Madison V, Chau AS, Loebenberg D, Palermo RE, McNicholas PM. Three-dimensional models of wild-type and mutated forms of cytochrome P450 14 $\alpha$-sterol demethylases from Aspergillus fumigatus and Candida albicans provide insights into posaconazole binding. Antimicrob Agents Chemother. 2004;48: 2124-2131.

55. Courtney R, Sansone A, Calzetta A, et al. The effect of a nutritional supplement (Boost ${ }^{\mathbb{B}}$ Plus) on the oral bioavailability of posaconazole. In: Program and Abstracts of the 43rd Interscience Conference on Antimicrobial Agents and Chemotherapy. 2003 Sept 14-17, Chicago, IL.
56. Courtney R, Wexler D, Radwanski E, et al. Effect of food on the relative bioavailability of two oral formulations of posaconazole in healthy adults. Br J Clin Pharmacol. 2004;57:218-222.

57. Wexler D, Laughlin M, Courtney R, et al. Effect of posaconazole on cytochrome P450 enzymes: a randomized, open-label, two-way crossover study. Eur J Pharm Sci. 2004;21:645-650.

58. Vazquez JA, Skiest DJ, Nieto L, et al. A multicenter randomized trial evaluating posaconazole versus fluconazole for the treatment of oropharyngeal candidiasis in subjects with HIV/AIDS. Clin Infect Dis. 2006;42:1179-1186.

59. Chavanet P, Lopez J, Grappin M, et al. Cross-sectional study of the susceptibility of Candida isolates to antifungal drugs and in vitroin vivo correlation in HIV-infected patients. AIDS. 1994;8:945-950.

60. Quereda C, Polanco AM, Giner C, et al. Correlation between in vitro resistance to fluconazole and clinical outcome of oropharyngeal candidiasis in HIV-infected patients. Eur J Clin Microbiol Infect Dis. 1996;15:30-37.

61. Maenza JR, Merz WG, Romagnoli MJ, Keruly JC, Moore RD, Gallant JE.Infection due to fluconazole-resistant Candida in patients with AIDS: prevalence and microbiology. Clin Infect Dis. 1997;24:28-34.

62. Dronda F, Alonso-Sanz M, Laguna F, et al. Mixed oropharyngeal candidiasis due to Candida albicans and non-albicans Candida strains in HIVinfected patients. Eur J Clin Microbiol Infect Dis. 1996;15:446-452.

63. Chryssanthou E, Torssandeer J, Petrini B. Oral Candida albicans isolates with reduced susceptibility to fluconazole in Swedish HIV-infected patients. Scand J Infect Dis. 1995;27:391-395.

64. Ginsburg CH, Braden GL, Tauber AI, Trier JS. Oral clotrimazole in the treatment of esophageal candidiasis. Am J Med. 1981;71:891-895.

65. De Wit S, Urbain D, Rahir F, Weerts D, Clumeck N. Efficacy of oral fluconazole in the treatment of AIDS associated oesophageal candidiasis. Eur J Clin Microbiol Infect Dis. 1991;10:503-505.

66. Laine L, Dretler RH, Conteas CN, et al. Fluconazole compared with ketoconazole for the treatment of Candida esophagitis in AIDS. A randomized trial. Ann Intern Med. 1992;117:655-660.

67. Laine L, Rabeneck L. Prospective study of fluconazole suspension for the treatment of oesophageal candidiasis in patients with AIDS. Aliment Pharmacol Ther. 1995;9:553-556.

68. Wilcox CM, Darouiche RO, Laine L, Moskovitz BL, Mallegol I, Wu J. A randomized, double-blind comparison of itraconazole oral solution and fluconazole tablets in the treatment of esophageal candidiasis. J Infect Dis. 1997;176:227-232.

69. Barbaro G, Barbarini G, Di Lorenzo G. Fluconazole compared with itraconazole in the treatment of esophageal candidiasis in AIDS patients: a double-blind, randomized, controlled clinical study. Scand J Infect Dis. 1995;27:613-617.

70. Barbaro G, Barbarini G, Calderon W, Grisorio B, Alcini P, DiLorenzo G. Fluconazole versus itraconazole for Candida esophagitis in acquired immunodeficiency syndrome. Gastroenterol. 1996;111:1169-1177.

71. Sheehan DJ, Hitchcock CA, Sibley CM. Current and emerging azole antifungal agents. Clin Microbiol Rev. 1999;12:40-79.

72. Ally R, Schurmann D, Kreisel W, et al. A randomized, double-blind, double-dummy, multicenter trial of voriconazole and fluconazole in the treatment of esophageal candidiasis in immunocompromised patients. Clin Infect Dis. 2001;33:1447-1454.

73. Lake DE, Kunzweiler J, Beer M, Buell DN, Islam MZ. Fluconazole versus amphotericin $\mathrm{B}$ in the treatment of esophageal candidiasis in cancer patients. Chemotherapy. 1996;42:308-314.

74. Barbaro G, Barbarini G, Di Lorenzo G. Fluconazole vs flucytosine in the treatment of esophageal candidiasis in AIDS patients: a double-blind, placebo controlled study. Endoscopy. 1995;27:377-383.

75. Cappelletty D, Eiselstein-McKitrick K. The echinocandins. Pharmacother. 2007;27:369-388.

76. Arathoon EG, Gotuzzo E, Noriega LM, Berman RS, DiNubile MJ, Sable CA. Randomized, double-blind, multicenter study of caspofungin versus Amphotericin B for treatment of oropharyngeal and esophageal candidiasis. Antimicrob Agents Chemother. 2001;33:1529-1535. 
77. Villanueva A, Gotuzzo E, Arathoon EG, et al. A randomized, doubleblind study of caspofungin versus fluconazole for the treatment of esophageal candidiasis. Am J Med. 2002;113:294-299.

78. de Wet NTE, Bester AJ, Viljoen JJ, et al. A randomized, double blind, comparative trial of micafungin (FK463) vs fluconazole for the treatment of oesophageal candidiasis. Aliment Pharmacol Ther. 2005;21:899-907.

79. Krause DS, Simjee AE, van Rensburg C, et al. A randomized, double-blind trial of anidulafungin versus fluconazole for the treatment of esophageal candidiasis. Clin Infect Dis. 2004;39:770-775.

80. Reef SE, Mayer KH. Opportunistic candidal infections in patients infected with human immunodeficiency virus: prevention issues and priorities. Clin Infect Dis. 1995;21 Suppl 1:S99-S102.

81. Vazquez JA, Skiest DJ, Tissot-Dupont H, Lennox JL, Boparai N, Isaacs R. Safety and efficacy of posaconazole in the long-term treatment of azole-refractory oropharyngeal and esophageal candidiasis in patients with HIV infection. HIV Clin Trials. 2007;8:86-97.

82. Stevens DA, Greene I, Lang OS. Thrush can be prevented in patients with acquired immunodeficiency syndrome and the acquired immunodeficiency syndrome-related complex. Randomized, double-blind, placebo-controlled study of 100-mg oral fluconazole daily. Arch Intern Med. 1991;151:2458-2464.

83. Powderly WG, Finkelstein DM, Feinberg J, et al. A randomized trial comparing fluconazole with clotrimazole troches for the prevention of fungal infections in patients with advanced human immunodeficiency virus infection. N Engl J Med. 1995;332:700-705.

84. Goldman M, Cloud GA, Wade KD, et al. A randomized study of the use of fluconazole in continuous versus episodic therapy in patients with advanced HIV infection and a history of oropharyngeal candidiasis. Clin Infect Dis. 2005;41:1473-1480.

85. Schuman P, Capps L, Peng G, et al. Weekly fluconazole for the prevention of mucosal candidiasis in women with HIV infection. A randomized, double-blind, placebo-controlled trial. Ann Intern Med. 1997;126:689-696.

86. Vazquez JA, Sobel JD. Epidemiologic overview of resistance to oral antifungal agents in the immunocompromised host. Excerpta Medica. Abstract, 1997;1-11.

87. Clinical and Laboratory Standards Institute. Reference method for broth dilution antifungal susceptibility testing of yeasts: 3rd Edition. Approved Standard M27-A3, Clinical and Laboratory Standards Institute, Wayne, PA, 2008.

88. Cameron ML, Schell WA, Bruch S, Bartlett JA, Waskin HA, Perfect JR. Correlation of in vitro fluconazole resistance of Candida isolates in relation to therapy and symptoms of individuals seropositive for human immunodeficiency virus type 1. Antimicrob Agents Chemother. 1993;37:2449-2453.

89. Revankar SG, Dib OP, Kirkpatrick WR, et al. Clinical evaluation and microbiology of oropharyngeal infection due to fluconazole-resistant Candida in human immunodeficiency virus-infected patients. Clin Infect Dis. 1998;26:960-963.

90. Horn CA, Washburn RG, Givner LB, Peacock JE Jr, Pegram PS. Azoleresistant oropharyngeal and esophageal candidiasis in patients with AIDS. AIDS. 1995;9:533-534.

91. Maenza JR, Keruly JC, Moore RD, Chaisson RE, Merz WG, Gallant JE. Risk factors for fluconazole-resistant candidiasis in human immunodeficiency virus-infected patients. $J$ Infect Dis. 1996;173:219-225.
92. McCarthy GM, Mackie ID, Koval J, Sandhu HS, Daley TD. Factors associated with increased frequency of HIV-related oral candidiasis. J Oral Pathol Med. 1991;20:332-336.

93. Parving H. Fluconazole suspension for oropharyngeal candidiasis unresponsive to tablets. Ann Intern Med.1997;126:332-333.

94. Philips P, Zemcov J, Mahmood W, Montaner JSG, Craib K, Clarke AM. Itraconazole cyclodextrin solution for fluconazole-refractory oropharyngeal candidiasis in AIDS: correlation of clinical response with in vitro susceptibility. AIDS. 1996;10:1369-1376.

95. Eichel M, Just-Nübling G, Helm EB, Stille W. Itraconazole suspension in the treatment of HIV-infected patients with fluconazole-resistant oropharyngeal candidiasis and esophagitis. Mycoses. 1996;39 Suppl 1: 102-106.

96. Cartledge JD, Midgley J, Gazzard BG. Itraconazole cyclodextrin solution: the role of in 6 vitro susceptibility testing in predicting successful treatment of HIV-related fluconazole-resistant and fluconazole-susceptible oral candidosis. AIDS. 1997;11:163-168.

97. Coppola S, Angarano G, Montagna MT, et al. Efficacy of itraconazole in treating AIDS-associated infections due to Candida krusei. Eur J Epidemiol. 1995;11:243-244.

98. Skiest DJ, Vazquez JA, Anstead GM, et al. Posaconazole for the treatment of azole-refractory oropharyngeal and esophageal candidiasis in subjects with HIV infection. Clin Infect Dis. 2007;44:607-614.

99. Ruhnke M, Schmidt-Westhausen A, Trautmann M. In vitro activities of voriconazole (UK-109,496) against fluconazole-susceptible and -resistant Candida albicans isolates from oral cavities of patients with human immunodeficiency virus infection. Antimicrob Agents Chemother. 1997;41:575-577.

100. Zingman BS. Treatment of mucosal candidiasis in HIV-infected patients. J Mycol Med. 1996;6:3-11.

101. Zingman B. Resolution of refractory AIDS-related mucosal candidiasis after initiation of didanosine plus saquinavir. [Letter] $N$ Engl J Med. 1996;334:1674-1675.

102. Vecchiarelli A, Monari C, Baldelli F, et al. Beneficial effect of recombinant human granulocyte colony-stimulating factor on fungicidal activity of polymorphonuclear leukocytes from patients with AIDS. J Infect Dis. 1995;171:1448-1454.

103. Swindells S, Kleinschmidt DR, Hayes FA. Pilot study of adjunctive GM-CSF (yeast-derived) for fluconazole-resistant oral candidiasis in HIV-infection. Infect Dis Clin Practice. 1997;6:278-279.

104. Vazquez JA, Gupta S, Villanueva A. Role of rhu-GM-CSF as adjunctive treatment of antifungal refractory oropharyngeal candidiasis in patients with AIDS. Eur J Clin Microbiol. 1998;17:781-783.

105. Vazquez JA, Vaishampayan J, Arganoza MT, Richards S, Boikov D, Sobel JD. Use of an over the counter product, Breathaway ${ }^{\circledR}$ (melaleuca oral solution), as an alternative agent for refractory oropharyngeal candidiasis in AIDS patients. AIDS. 1998;12:1033-1037.

106. Smith DE, Midgley J, Allan M, Connolly GM, Gazzard BG. Itraconazole versus ketoconazole in the treatment of oral and oesophageal candidosis in patients infected with HIV. AIDS. 1991;5:1367-1371.

107. Barchiesi F, Giacometti A, Arzeni D, et al. Fluconazole and ketoconazole in the treatment of oral and esophageal candidiasis in AIDS patients. J Chemother. 1992;4:381-386.

108. de Repentigny L, Ratelle J. Comparison of itraconazole and ketoconazole in HIV-positive patients with oropharyngeal or esophageal candidiasis. Chemotherapy. 1996;42:374-383.

HIV/AIDS - Research and Palliative Care

\section{Publish your work in this journal}

HIV/AIDS - Research and Palliative Care is an international, peerreviewed open-access journal focusing on advances in research in HIV, its clinical progression and management options including antiviral treatment, palliative care and public healthcare policies to control viral spread. The journal welcomes original research, basic science,

clinical \& epidemiological studies, reviews \& evaluations, expert opinion \& commentary, case reports \& extended reports. The manuscript management system is completely online and includes a very quick and fair peer-review system. Visit http://www.dovepress.com/ testimonials.php to read real quotes from published authors. 